\title{
ACTIVIDAD HISTÓRICA Y ANÁLISIS DE LA AMENAZA DEL VOLCÁN TURRIALBA, COSTA RICA
}

\author{
HISTORIC ACTIVITY AND HAZARD ANALYSIS OF TURRIALBA VOLCANO, \\ COSTA RICA
}

\author{
Gino González ${ }^{1,2,3 *}$, Raúl Mora-Amador ${ }^{1,2,3}$, Carlos Ramírez ${ }^{1,2,3}$, \\ Dmitri Rouwet ${ }^{4}$, Yemerith Alpizar ${ }^{1}$, Cristian Picado ${ }^{2,3} \&$ Rolando Mora ${ }^{2}$ \\ ${ }^{1}$ Centro de Investigaciones en Ciencias Geológicas (CICG), Universidad de Costa Rica \\ ${ }^{2}$ Escuela Centroamericana de Geología, Universidad de Costa Rica. \\ ${ }^{3}$ Red Sismológica Nacional (RSN), Universidad de Costa Rica. \\ ${ }^{4}$ Istituto Nazionale di Geofisica e Vulcanologia (INGV), sezione di Bologna, Italia \\ *Autor para contacto: ginovolcanico@gmail.com
}

(Recibido: 31/07/2011; aceptado: 18/09/2014)

\begin{abstract}
The historic activity of Turrialba volcano was studied based on traveler's reports and newspapers of the $19^{\text {th }}$ century. In 1864-1866, the volcano was in a period of magmatic eruptions which can be subdivided in two stages: pre-eruptive and eruptive. Ash fall reached distances of $\sim 115 \mathrm{~km}$ covering an area of $3400 \mathrm{~km}^{2}$. By means of GIS, we estimated how a similar magmatic eruption as this, could affect the present population and infrastructure, and we conclude that the ash would fall in the most populated areas of Costa Rica, which is important as a prevention measure and an analysis of future risk decision-making.

In 2005, Turrialba volcano increased its seismic activity, gas emissions and acid rain, which affected the S, SW and $\mathrm{W}$ sectors of the volcano. Afther more than a century without eruption, on 5 January 2010 phreatic activity resumed, with emissions of non-juvenile ash which reached San José. The ash contained cristobalite and hematite, which are unhealthy. Moreover, the eruption formed a nested crater of $\sim 125 \mathrm{~m} \mathrm{x} \sim 45 \mathrm{~m}$ with a NW-SE direction, with emission of $\mathrm{SO}_{2}$ in state of combustion and incandescence, and manifested sporadic ash eruptions. In June 2011, a fumarolic area appeared with temperatures up to $\sim 530{ }^{\circ} \mathrm{C}$ in the NW intracrater. On 11 January 2012 , a sulfur flow occurred ( $175 \mathrm{~m}$ long), produced by the heating of the system which also led to phreatic eruptions on 12 and 18 January 2012. Another crater was formed in the eastern extreme of the NW crater.
\end{abstract}

Key words: Volcanic gases, ash, phreatic eruption, termography, GIS, Turrialba volcano.

RESUMEN: Se conoce la actividad histórica del volcán Turrialba, gracias a los relatos de viajeros y noticias del siglo XIX. En 1864-1866, el Turrialba estuvo en un periodo eruptivo magmático, el cual se analizó en dos etapas: pre- eruptivo y eruptivo. La ceniza llegó a $\sim 115 \mathrm{~km}$ de distancia, cubriendo un área de $3400 \mathrm{~km}^{2}$. Se calculó por medio de un

GONZÁlEZ, G., MORA-AMADOR, R., RAMÍREZ, C., ROUWET, D., PICADO, C. \& MORA, R., 2015: Actividad histórica y análisis de la amenaza del volcán Turrialba, Costa Rica.- Rev. Geol. Amér. Central, 52: 129-149, DOI: 10.15517/rgac. v0i52.19033 
SIG cómo una erupción magmática similar a esta, podría afectar a la presente población e infraestructura, y se concluyó que la ceniza caería en los sectores de mayor población de Costa Rica, esto es importante como medida de prevención y análisis para la futura toma de decisiones.

En 2005, el volcán Turrialba incrementó la cantidad de sismos, emisión de gases y lluvia ácida, produciendo una mayor afectación en los sectores ubicados al S, SW y W del volcán. Luego de más de un siglo sin tener erupciones, el 5 de enero del 2010, comenzó un período eruptivo freático, con emisión de cenizas no juveniles, que llegaron hasta San José. Esta ceniza contiene cristobalita y hematita, los cuales son perjudiciales para la salud. Además, esta erupción formó una boca intracratérica de $\sim 125 \mathrm{~m} \mathrm{x} \sim 45 \mathrm{~m}$ de dirección NW-SE, con emisión de $\mathrm{SO}_{2}$ en estado de combustión, incandescencia y esporádicas salidas de ceniza. En junio del 2011, apareció una zona fumarólica a $\sim 530^{\circ} \mathrm{C}$ en el intracráter NW. E1 11 de enero del 2012, apareció un flujo de azufre (175 m de largo), producto de un sobre calentamiento en el sistema, que resultó en un nuevo periodo de erupciones freáticas los días 12 y 18 de enero del 2012. Esta erupción formó otra boca en la pared externa E del cráter NW.

Palabras clave: Gases volcánicos, ceniza, erupciones freáticas, termografía, SIG, volcán Turrialba.

\section{INTRODUCCIÓN}

Antes de 1821, Costa Rica formaba parte de la Capitanía General de Guatemala. Costa Rica se caracterizaba por un singular abandono por parte de la corona española, con una economía de subsistencia y alta pobreza (Guillén, 1988), ocasionando un atraso en la educación del país y de ahí la escasez de documentación o reportes de alguna actividad volcánica en Costa Rica.

La mayoría de los relatos históricos sobre volcanes, fueron hechos por viajeros que visitaban el país por un tiempo limitado. El primer texto que se conoce sobre actividad volcánica en Costa Rica es del año 1723, escrito por el gobernador Diego de la Haya, describiendo la erupción del volcán Irazú y además, se menciona actividad de desgasificación en el volcán Turrialba: "sajado y reventado ha muchos años, el cual humea por años sin hacer daño alguno en sus contornos". Para conocer la situación del volcán Turrialba, se enviaron observadores al poblado de Ujarrás ( $\sim 15 \mathrm{~km}$ de distancia del volcán), y ellos comentan que en la noche "...se vió arrojar mayor fuego con cuadriplicadas porciones de grandes piedras encendidas" (Tristán, 1924).

El volcán Turrialba se encuentra en la Cordillera Volcánica Central (CVC) a unos $35 \mathrm{~km}$ de San José (figura 1a), su altura es de $3340 \mathrm{~m}$ s.n.m., se clasifica como un estratovolcán complejo (Alvarado, 2009) que posee tres cráteres alineados NW-SE (Fig. 1b-c), siendo el cráter NW, también llamado Murciélago, el más activo (Mora, 2001). Reagan et al. (2006) explican que las rocas del volcán Turrialba se caracterizan por ser basaltos, andesitas y dacitas ricas en K y flujos piroclásticos con pómez. El último evento pliniano se dio en 1970 A. P.

La única erupción magmática histórica que se conoce, ocurrió entre los años 1864-1866. Previo a este evento, se dieron reportes de actividad de desgasificación al menos desde 1847 (Oersted, 1863), con esporádicas erupciones freáticas. Al mes de marzo del 2012, el volcán Turrialba presentaba fuerte actividad fumarólica, con gases a altas temperaturas, incandescencia, lluvia ácida y ocasionales erupciones freáticas, por lo que algunos pobladores ubicados al S, SW y W del volcán, han tenido que abandonar sus hogares.

\section{METODOLOGÍA}

Esta investigación divide la erupción magmática de 1864-1866 en dos etapas: pre- eruptiva (1847-1864) y eruptiva (1864-1866), basada en relatos, revistas, ilustraciones y noticias compiladas, con una interpretación de esta información. 

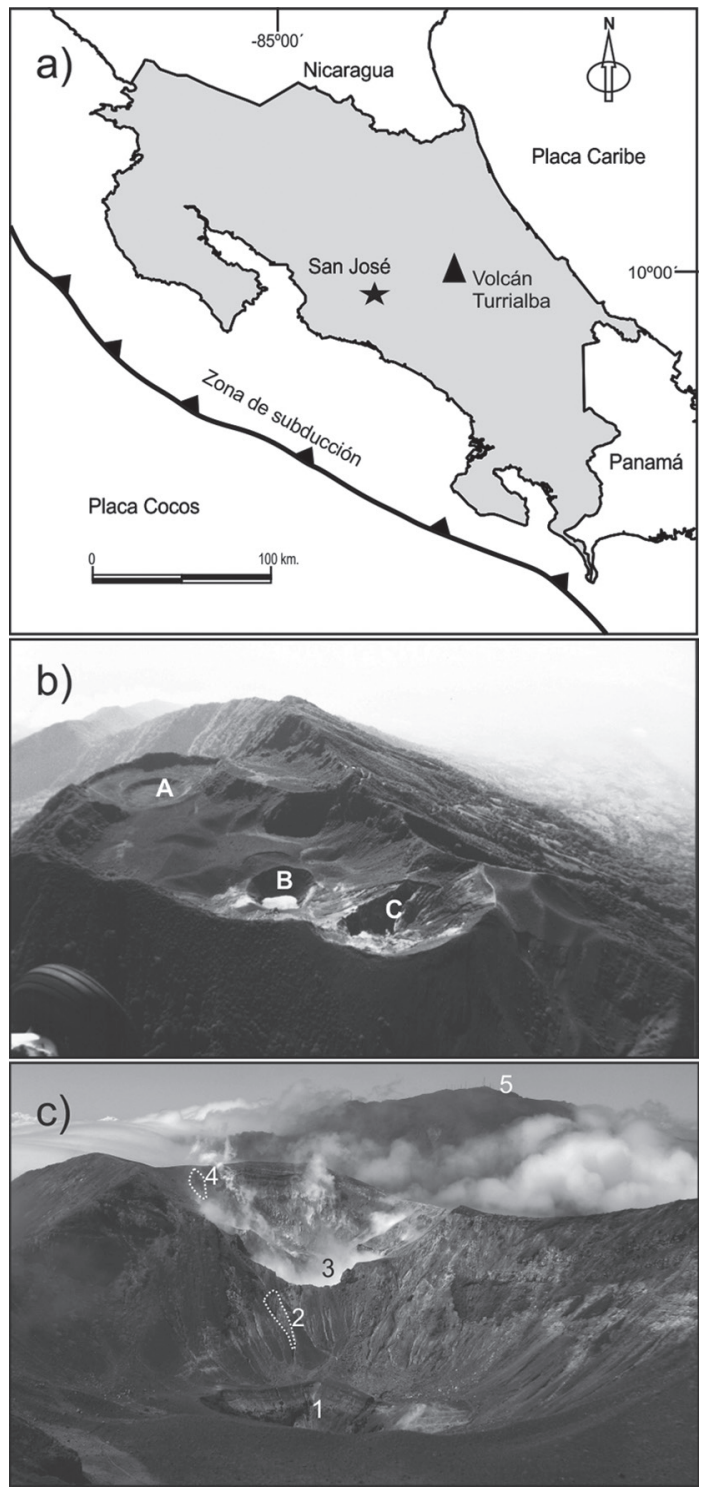

Fig. 1: Mapa de ubicación del volcán Turrialba y fotografías de los cráteres y estructuras del volcán Turrialba. a Mapa de ubicación del volcán Turrialba, con triángulo negro: volcán Turrialba, con estrella negra: San José. b Fotografía área con la ubicación de los cráteres del volcán Turrialba: A. Cráter Noreste; B. Cráter Central; C. Cráter Suroeste o Murciélago. c Fotografía tomada desde el cráter NE del volcán Turrialba, se muestran las estructuras: 1. Cráter Central; 2 Fumarola Árbol Quemado; 3. Cráter Suroeste o Murciélago; 4. Boca intracratérica formada el 8 de enero del 2010 llamada Boquete 1-2010; 5. Volcán Irazú.
Se dividió de esta manera, debido a que los datos históricos muestran cómo el volcán Turrialba iba aumentando paulatinamente su actividad, hasta hacer erupción en 1864-1866, por lo que didácticamente facilita su comprensión y análisis.

Para describir la actividad volcánica reciente, la metodología y técnicas que se utilizaron son: (1) visitas de campo y observaciones periódicas desde 1998, (2) muestreos geoquímicos de las fumarolas del cráter NW y lagunas efímeras, (3) medición de temperatura de las fumarolas y lagos con un sensor remoto, el cual utiliza la técnica de la termografía, que consiste en mediciones exactas a distancia, por medio del espectro electromagnético del infrarrojo, cuya longitud de onda es 0,7 a $100 \mathrm{~mm}$ (Edgar Hidalgo, comunicación oral, 2011). El equipo térmico infrarrojo utilizado, es la cámara portátil FLIR ${ }^{(}$(Forward Looking Infrared Radiometer) modelo P660, con rango de medición de -20 a $500{ }^{\circ} \mathrm{C}$ (opcional hasta $2000{ }^{\circ} \mathrm{C}$ ) y resolución de $\pm 1{ }^{\circ} \mathrm{C} \mathrm{o} \pm 1 \%$ de la lectura. Las correcciones internas que se deben aplicar a la cámara son la temperatura reflejada, distancia del objeto, temperatura óptica externa; para el factor de emisividad se tomó como valor 0,95 para las superficies de rocas calientes y 0,96 para la pluma de gas (Hernández et al., 2007; Spampinato et al., 2010; Ramírez et al., 2011). La temperatura atmosférica y porcentaje de humedad relativa, se midieron con el mini termo-anemómetro portátil Extech ${ }^{\circledR}$ 45158. Una vez hechas las mediciones en el campo, se corrigieron los datos en el software FLIR ${ }^{\circledR}$ Reporter. (4) Análisis de la ceniza caída del 5 de enero del 2010, utilizando difracción de energía de rayos $\mathrm{X}$ y difractometría de rayos X, (5) mapa de caída de ceniza de 18641866, basado en los relatos y reportes históricos de noticias; para ello se utilizó el sistema de información geográfica (SIG) Arc Gis ${ }^{\circledR} 9.3$ y con la base de datos del censo del año 2000, se obtuvo la infraestructura (hospitales, clínicas, bomberos), instituciones (centro educativos) y población amenazada si ocurriese un evento eruptivo similar actualmente; y además (6) se elaboró un mapa lluvia ácida y caída de ceniza para la erupción 
freática del 2010, con base en datos de campo y reportes de la Comisión Nacional de Emergencias (CNE), informes de la Red Sismológica Nacional (RSN) y el Centro de Investigaciones en Ciencias Geológicas (CICG).

\section{ERUPCIÓN MAGMÁTICA 1864-1866}

\section{Etapa pre- eruptiva}

El inicio exacto de esta etapa no se puede precisar, pero al menos desde el año 1847 (Figura 2a), se reporta actividad en el volcán Turrialba, a cargo del viajero Oersterd (1863) “...se observan muchas grietas por donde escapan continuamente humo y vapores". Posteriormente, Marr (1853) describe en su visita al poblado de Turrialba que “...era un espectáculo peculiar ver danzar, al parecer la majestuosa columna de humo sobre las verdes copas de los árboles, a la vez que, de vez en cuando, un retumbo revelaba la actividad de su hoguera". Asimismo, los relatos de Wagner \& Scherzer (1853) explican que "exhala casi sin interrupción ya más ligeras ya más fuertes bocanadas de humo y parece aún arrojar escorias incandescentes". El viajero Karl Hoffmann (1856), describe en dos ocasiones actividad en el volcán Turrialba, primero cuando asciende en mayo de 1855 al volcán Irazú y escribe que “...vimos elevarse del volcán Turrialba tres columnas de humo verticales como cirios a cuyo lado también pudimos distinguir claramente, por medio de anteojos de larga vista, llamas que seguramente subian desde otras tantas aberturas"; luego en agosto de ese mismo año, sube al volcán Barva y describe "el siempre humeante cono del Turrialba". Además, Trollope (1859) comenta sobre el Turrialba que “...siempre está despidiendo fuego $y$ chorros de piedra derretida", este relato es a su vez, confirmado por Meagher (1860; figura 2b); von Frantzius (1861) comenta sobre el Turrialba que en las noches oscuras "....se dice que se puede percibir fogatas que salen del volcán”.

El 22 de febrero de 1864, inició el primer ascenso hasta la cima del volcán Turrialba, a cargo de los señores Rocha de la Tour, Antolino Quesada, Manuel Guillén y Juan Braun (relator del ascenso). Ellos fueron enviados por el gobierno de Costa Rica, para informar sobre lo que sucedía en el volcán Turrialba. Llegan 4 días más tarde y observan " 4 paredes negras y amarillas, en que más de 100 bocas (2 varas de circunferencia) adornadas a su alrededor con capas amarillas de azufre, están humeando con estrépito", además apuntan que "... del lado Oeste y Este, de donde sale en dos bocas más grandes, mucho más humo con ruidosa fuerza". Ellos calcularon la columna de gas en 500 pies de altura, 100 varas de diámetro y que afectaba la vegetación circundante (La Gaceta 12-3-1864) “... no hay vegetación, sino un poco hacia el sur, donde no llega el humo, de yerbas y gramas de muy raquitica apariencia".

Sobre la altura de la columna de gas, Hoffmann (1856) explica que el volcán Turrialba era utilizado por viajeros marítimos y libros de navegación para entrar a San Juan del Norte; von Frantzius (1861) comenta que sus gases se observan desde los Montes del Aguacate y Juan Braun acota que desde Heredia (La Gaceta 12-3-1864).

\section{Etapa eruptiva}

A partir del 17 de agosto de 1864, inicia la primera erupción magmática histórica conocida de este volcán (Pittier, 1888). De esta erupción, hay varios relatos que permiten tener una idea $\mathrm{e}$ interpretar cual fue su magnitud. Los primeros reportes de caída de ceniza se dan en San José, Atenas y Grecia del 16 al 20 de setiembre de 1864 (La Gaceta 2-10-1864; 9-10-1864), el señor Luciano Platt hizo un análisis químico de esta ceniza (La Gaceta 25-9-1864) el cual se muestra en el cuadro 1.

Para determinar cuál era la situación del Turrialba, el gobierno de Costa Rica envió a los señores Antolino Quesada y Manuel Guillén, quienes ascendieron previamente en febrero de 1864. Ellos llegaron a la cima el 30 de setiembre de 1864 (La Gaceta 9-10-1864) y observaron “...una columna de humo que se elevaba a una altura dos veces mayor que la que se alzaba en el mes de febrero", sobre esta columna de gas explican que "... era negra y verde y se levantaba y salía de esta torre de humo envolviendo inmensas llamaradas de fuego, 


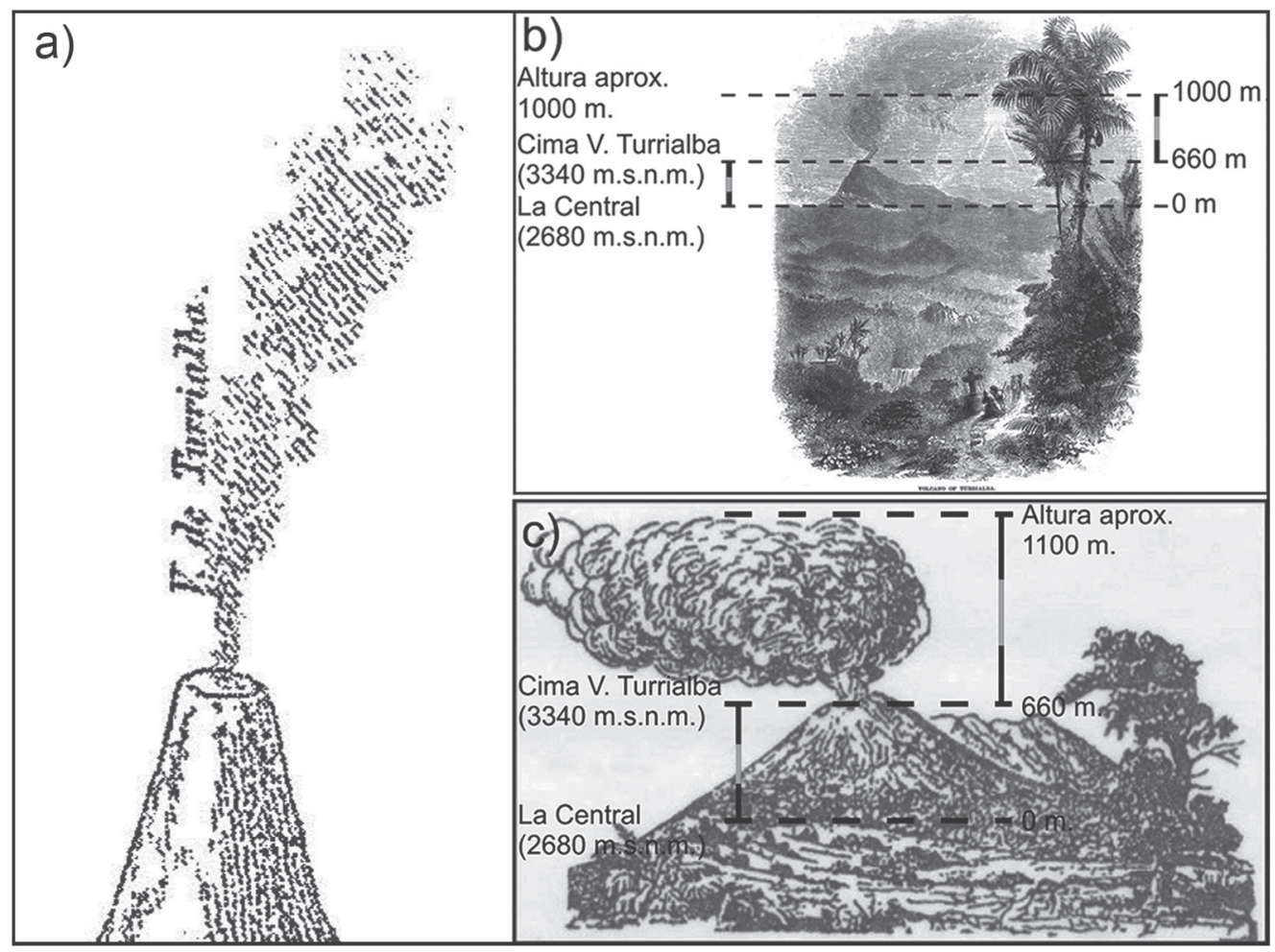

Fig. 2: Ilustraciones del volcán Turrialba del siglo XIX. a Ilustración del volcán Turrialba de 1847, el cual está desgasificando, tomada de Oersted (1863). b Ilustración tomada de Meagher (1860) del volcán Turrialba, se sobrepone una interpretación de la posible altura de la columna de gases. c Ilustración tomada de von Seebach (1865) del volcán Turrialba, se sobrepone una interpretación de la posible altura de la columna de gases.

azuladas, con estrépito terrible, como si la tierra quisiera producir otro volcán". Las paredes internas del cráter eran "...amarillas o negras, como barnizadas con pez". Del material expulsado, comentan que el mayor espesor de ceniza estaba del lado N del volcán "....basta considerar que toda la superficie de este ancho volcán está cubierto con una capa de más de una vara de espesor con ceniza que se ha regado visiblemente sobre una extensión de más de tres leguas alrededor y principalmente al Norte del volcán". En ese mismo año, el señor Blas Moya (Peraldo \& Mora, 2008), escribe una nota al Ministro de Gobernación el 19 de octubre explicando"...que hace diez dias estaba el río blanco de azufre, y que era tanta la mortandad de peces que habia en las playas que se podían sacar en carretadas". Este relato concuerda con la escrito por Antolino Quesada y Manuel Guillén "Al lado Oeste del volcán y como a 500 varas bajo el cráter ha nacido un río, cuyas aguas son sumamente ácidas tal vez con ácido sulfúrico" (La Gaceta 9-10-1864).

Nuevos reportes de caída de ceniza ocurren del 24 al 31 de enero de 1865 y se extendió a $\sim 30 \mathrm{~km}$ de distancia al NW de San José (La Gaceta, 4-2-1865; von Seebach, 1865) y se dice que "... se pudo juntar un saquito de esta ceniza" y que además se oían fuertes retumbos (von Seebach, 1865). En su afán por conocer que sucedía, von Seebach asciende al volcán Turrialba en marzo de 1865, en compañía de Antolino Quesada. Ellos comentan las dificultades para subir al volcán debido a la gran cantidad de ceniza que caía; estando en la cima, describen un solo cráter activo de unos $400 \mathrm{~m}$ de diámetro, cubierto de ceniza y rocas; que constantemente tenía explosiones “... se oía cada 30 segundos un ruido parecido al estallido de una escopeta, 
Cuadro 1

Análisis químico de la ceniza del volcán Turrialba expulsada en 1864, hecho por el señor Luciano Platt. Tomado de La Gaceta del 25 de setiembre de 1864

\begin{tabular}{cc}
\hline Compuesto químico & $\%$ \\
\hline Sílice y varias tierras silíceas & 94 \\
Hierro sulfurado & 4 \\
Polvos orgánicos del aire & 1 \\
Cal y sal del mar & 1 \\
\hline
\end{tabular}

causada por las masas de piedra que la erupción arrojaba contra las paredes de la inmensa chimenea". Las rocas expulsadas caían nuevamente en el cráter y la pluma de gas era de al menos 1000 $\mathrm{m}$ de altura con dirección SW (fig. 2c).

Según Sapper (1942), las últimas y más violentas erupciones sentidas en este periodo, fueron en enero y febrero de 1866, que inclusive cayó ceniza en Puntarenas, a $\sim 115 \mathrm{~km}$ de distancia del volcán Turrialba (Pittier, 1888). Fernández (1921) hace un comentario sobre la discrepancia de opinión entre von Seebach y Félix Belly, este último decía que la ceniza del volcán Turrialba llegó hasta Realejo, Nicaragua, ( $450 \mathrm{~km}$ de distancia). Sapper (1942) apoya esta idea, pero von Seebach comenta que es poco probable, debido a la dirección predominante de los vientos.

Para Pittier (1888) las últimas erupciones fueron en mayo de 1866 “....esta empezó el 1 de febrero y fué acompañada de muchos temblores (8 de mayo) y se sintieron hasta en San José"; estos son los últimos reportes de caída de ceniza del volcán Turrialba del periodo magmático 1864-1866.

Luego de tres años de haber terminado la erupción, en 1869 Pittier (1888) asciende al volcán Turrialba, él describe el cráter NW con dos bocas intracratéricas y escape de gases sulfurosos en la pared norte, pero sin mayor actividad. Polakowsky (1876) dice que "El Turrialba en su lejanía no daba señal perceptible de vida, en noviembre de 1875 " y Sapper (1942) visita la cima del Turrialba en 1899 y reporta fumarolas de baja temperatura.

\section{Análisis de los períodos pre- eruptivo y eruptivo de la erupción de 1864-1866}

Los viajeros reportan retumbos (Marr, 1853; Trollope, 1859; von Seebach, 1865), incandescencia similar a una hoguera y colores azulados en el volcán; estas descripciones se asocian respectivamente a sismos superficiales, escape de gases a altas temperaturas $\left(\sim 500{ }^{\circ} \mathrm{C}\right.$; fig. 3$)$ y azufre en estado de combustión (Reagan et al., 2006; Yuri Taran, comunicación oral; Mora et al., 2011a) y es posible que estos eventos estaban acompañados por periodos de erupciones freáticas (fig. 3). Acerca de la columna de ceniza, algunos relatos comentan que era de 500 pies de altura y 100 varas de ancho ( $\sim 150 \mathrm{~m} \mathrm{x} \sim 85 \mathrm{~m}$ ), con fuerte sonido (La Gaceta 12-3-1864). Sin embargo, Meagher (1860) hace una ilustración del Turrialba en la que puede calcular una columna de gas en al menos $1000 \mathrm{~m}$ altura sobre el borde del volcán (fig. 2b), que se observaba desde el volcán Irazú ( 10 km), Heredia $(\sim 40 \mathrm{~km})$ y los cerros del Aguacate $(\sim 65 \mathrm{~km})$.

Algunos de estos relatos, son comparables con lo que ocurre hasta marzo del 2012 en el cráter NW del volcán Turrialba, debido a que hay esporádicas caídas de ceniza, azufre en estado de combustión e incandescencia. Este último fenómeno, se ha reportado recientemente en los volcanes Aso, Santa Ana y Poás (Miyabuchi et al., 2008; Scolamacchia et al., 2010; Mora et al., 2011b). Igualmente, la altura de la pluma de gas descrita, es similar a las actuales y estas dependen de la velocidad y dirección predominante del viento. Los colores que describe Juan Braun (La Gaceta 12-3-1864) y posteriormente Antolino Quesada y Manuel Guillén sobre las fumarolas (La Gaceta 9-10-1864), corresponden con temperaturas $<250$ ${ }^{\circ} \mathrm{C}$ en el caso del amarillo y los negros estilo barniz son de temperaturas $>250{ }^{\circ} \mathrm{C}$, debido a que el azufre cambia de color en dependiendo de la temperatura (Meyer, 1976; Theilig 1982).

El periodo eruptivo inicia el 17 de agosto de 1864 (Pittier, 1888; fig. 3), la ceniza llegó a $\sim 65$ km de distancia del volcán (San José se ubica a $\sim 35 \mathrm{~km}$ 


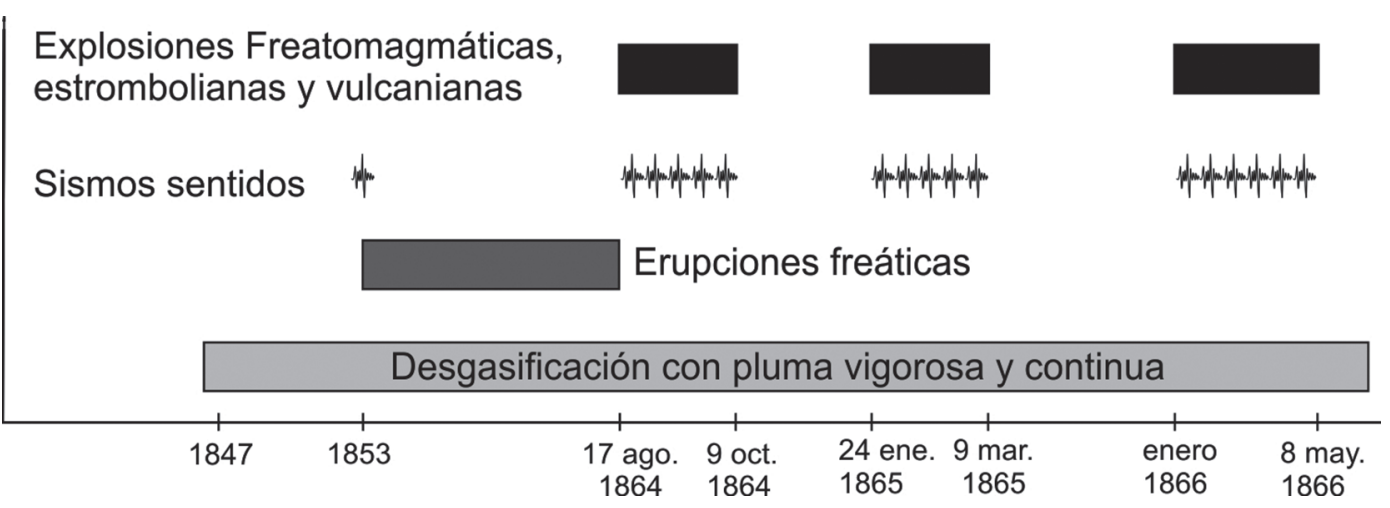

Fig. 3: Síntesis de los periodos pre eruptivo y eruptivo de la erupción de 1864-1866.

del volcán), con un espesor aproximado de $\sim 1 \mathrm{~m}$ en sus alrededores (La Gaceta 9-10-1864).

El río ácido que se comenta es el río Toro Amarillo, nace a unos $500 \mathrm{~m} \mathrm{~N}$ del volcán Turrialba. El aumento en su acidez, se da porque los gases ácidos expulsados como el $\mathrm{SO}_{2}$ y $\mathrm{HCl}$ se condensaron con la lluvia y se dio una disminución del $\mathrm{pH}$ en el agua, provocando la muerte de los peces.

El 24 de enero de 1865, hay un pulso importante en la actividad eruptiva (von Seebach, 1865; fig. 3), la ceniza llegó a $\sim 65 \mathrm{~km}$ de distancia del volcán (La Gaceta, 4-2-1865; von Seebach, 1865), por lo tanto se infiere, que este evento fue similar al ocurrido en 1864, en términos de extensión por caída de ceniza.

Posteriormente, Pittier (1888) explica que la mayor caída de ceniza fue a inicios de 1866, y llegó hasta Puntarenas, que se encuentra a $\sim 115$ $\mathrm{km}$ de distancia del volcán, cubriendo un área aproximada de $3400 \mathrm{~km}^{2}$ (fig. 4a). Esta erupción según Reagan et al. (2006), se clasifica como freática durante el primer año y luego freatomagmática, estromboliana y vulcaniana para 1865 a 1866 (fig. 3). Esto coincide, con el "... ruido parecido al estallido de una escopeta" (von Seebach, 1865) y la altura a la que llegaban los piroclastos (de 100 a $1000 \mathrm{~m}$ sobre el borde del cráter; La Gaceta 9-10-1864; von Seebach 1865; fig. 2c), dado que, estas características se consideran como proyección balística asociada a eventos estrombolianos y vulcanianos (Francis \& Oppenheimer, 2004; Schmincke, 2004).

Para describir el Índice de Explosividad Volcánica (VEI por sus siglas en inglés; Newhall \& Self, 1982) de la erupción magmática de 18641866, Soto (1986) comenta que estas explosiones fueron poco energéticas y Reagan et al. (2006) proponen un VEI de 3 o menor. Proponemos un valor del VEI $=2$, cuyo análisis se muestra en el cuadro 2 y está basado en la metodología de Newhall \& Self (1982), la cual consiste en: (1) descripción general, (2) estimación del volumen de material expulsado que para Reagan et al. (2006) fue $\leq$ $3 \times 10^{7} \mathrm{~m}^{3}$, para nosotros, este volumen expulsado pudo ser inferior, apoyado en la descripción de los relatos y extensión de los mayores espesores de ceniza, (3) altura de la columna de ceniza sobre el nivel del cráter, (4) descripción cualitativa, (5) duración y (6) tipo de erupción.

\section{ERUPCIÓN DE 2010}

\section{Etapa pre- eruptiva}

En las últimas dos décadas, las fumarolas del volcán Turrialba se han mantenido a una temperatura de $\sim 90{ }^{\circ} \mathrm{C}$ (RSN-UCR, 1991, 1995, 2001; Mora, 2001, 2003, 2004; Paniagua, 2002; Mora 
Cuadro 2

Análisis del valor VEI $=2$, propuesto para la erupción de 1864-1866, basado en la descripción general, estimación del volumen de material expulsado, altura de la columna de ceniza, descripción cualitativa, duración y tipo de erupción

\begin{tabular}{cc}
\hline Descriptor & Detalle \\
\hline Descripción general & Moderada \\
Volumen de ceniza & $\leq 3 \times 10^{7} \mathrm{~m}^{3}$ \\
Altura de la columna & $1,1 \mathrm{~km}$ sobre el cráter \\
Descripción cualitativa & Explosiva \\
Duración & Esporádicas explosiones \\
Tipo de erupción & Freatomagmática a \\
& estromboliana y vulcaniana \\
\hline
\end{tabular}

et al., 2004; Vaselli et al., 2010), con aumentos importantes a partir del 2002, año en que apareció al costado E del cráter Murciélago (NW), la fumarola llamada Árbol Quemado (Figura 2c), con rumbo $210^{\circ}$, la cual coincide con la dirección de la falla Ariete. En este lugar ha sido tomada la mayoría de los datos de temperatura, $\mathrm{pH}$ y de gases. A su vez, en ese mismo año, también aumentó la emisión de gases y por ende la lluvia ácida (Mora, 2003), provocando que los murciélagos del cráter NW desaparecieran y la vegetación circundante a este cráter fuera quemada.

En junio del 2005, la actividad fumarólica y la temperatura aumentaron considerablemente, provocando la muerte de vegetación en la ladera W del volcán (Hilton et al., 2010). En el año 2007, aparecen nuevas fumarolas a temperaturas $>100$ ${ }^{\circ} \mathrm{C}$, acompañadas de una sismicidad máxima de $\sim 100$ microsismos diarios (Mora \& Rojas, 2007). Este tipo de sismicidad se puede asociar a aspectos como: (1) movimiento de fluidos hidrotermales, (2) sismos volcano-tectónicos profundos o (3) ruptura de roca combinado con circulación de fluidos (Mora et al., 2001). En el año 2009, el volcán Turrialba volvió a aumentar la actividad sísmica ( $\sim 70$ microsismos diarios y mayor ruido volcánico; Barquero \& Rojas, 2010) y debido a estos cambios en la actividad volcánica, la RSN elaboró un Semáforo Volcánico y estableció al volcán Turrialba en alerta verde tipo 2a (cambios en el comportamiento de la actividad volcánica).

La fumarola Árbol Quemado en diciembre del 2009 se ensanchó, aumentando la salida de gases, con temperatura $>250{ }^{\circ} \mathrm{C}$ y continuó la aparición de nuevas grietas con escape de gases (Rojas $\&$ Peraldo, 2009). Además, en los tres cráteres del volcán Turrialba (fig. 1b) se formaron lagunas efímeras frías $\left(\sim 15^{\circ} \mathrm{C}\right)$, con una conductividad promedio de $1,7 \mathrm{mS} / \mathrm{cm}$, alta concentración de $\mathrm{SO}_{4}$ (758 mg/L) y un pH < 3,5 (Ramírez et al., 2010; Rouwet et al., 2010; Rouwet et al., 2011).

\section{Etapa eruptiva}

El 5 de enero del 2010, luego de 143 años sin tener algún tipo de actividad eruptiva, el volcán Turrialba inicia un periodo de erupciones freáticas, la cual genera dos bocas intracratéricas con rumbo $320^{\circ}$ en el cráter NW (fig. 5a).

Las dos bocas intracratéricas formadas por esta erupción, se unieron el 8 de enero del 2010, formando una sola, a la cual se le nombró Boquete 1-2010. Los números del nombre significan el mes en que aparece (enero=1) y el año (2010). Estas bocas y su unión se muestran en las figuras 1c, 5a-b y 6a-b. El Boquete 1-2010 medía 120 $\mathrm{m}$ de diámetro mayor, $30 \mathrm{~m}$ de diámetro menor (González et al., 2010), además tenía erupciones de ceniza esporádicas (ceniza y lapilli), constante escape de gases de tonalidades cafés (combinación de gases con ceniza) y azulados por el $\mathrm{SO}_{2}$ en estado de combustión (Reagan et al., 2006; Yuri Taran comunicación oral, 2011; Mora et al., 2011b) y una temperatura de $\sim 560{ }^{\circ} \mathrm{C}$. Ese 8 de enero del 2010, la ceniza llegó hasta Aserrí, a $\sim 40$ km de distancia del volcán, cubriendo un área aproximada de $500 \mathrm{~km}^{2}$ (fig. 4b). La altura de la columna de gas llegó hasta los $2 \mathrm{~km}$ por encima del cráter (Soto et al., 2010) y era observada desde Alajuela, Heredia, Atenas y hasta el Cerro de la Muerte.

En febrero y marzo del 2010, la ceniza expulsada fue mínima y su origen se debe al colapso y erosión de las paredes internas del Boquete 


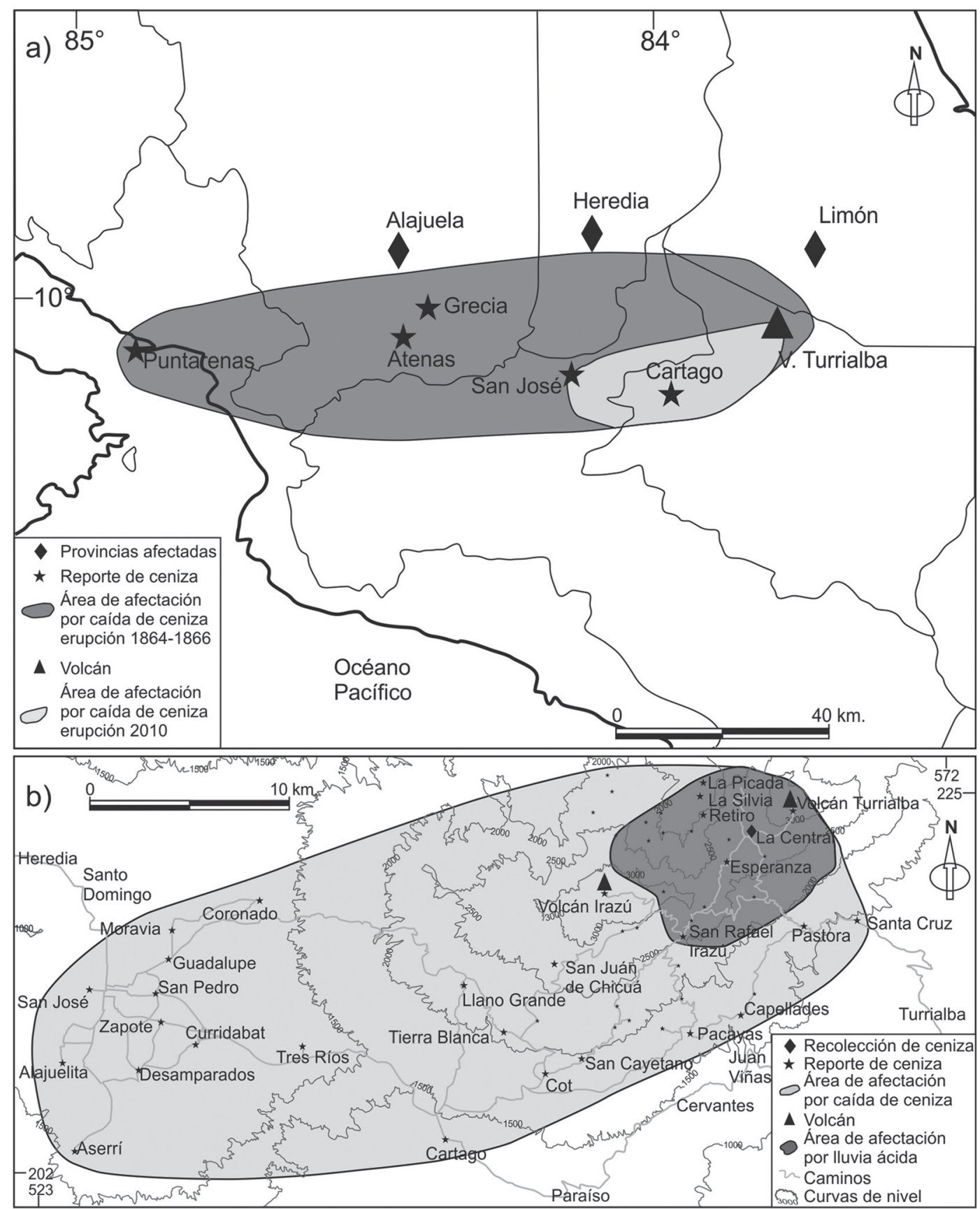

Fig. 4: Mapas de caída de ceniza de las erupciones 1864-1866 y 2010. a Áreas afectadas por caída de ceniza de las erupciones de 1864-1866 (gris oscuro) y 2010 (gris claro). b Detalle de la caída de ceniza (gris claro) y lluvia ácida (gris oscuro) de la erupción del 5 de enero del 2010. 

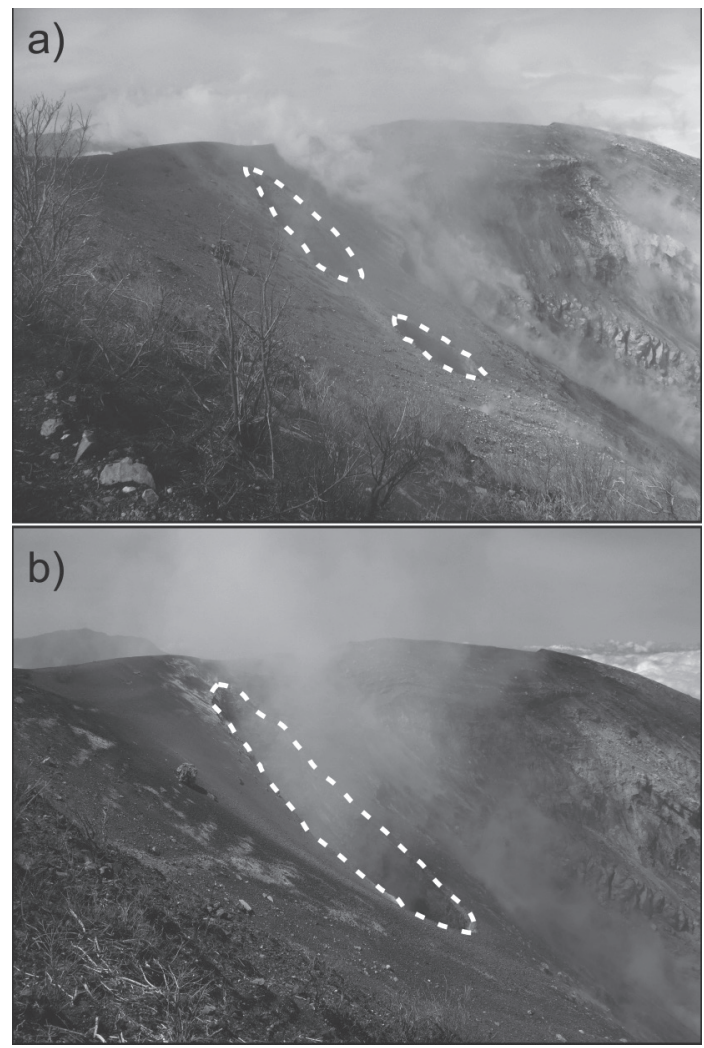

Fig. 5: Cráteres en el intracráter Noroeste o Murciélago. a Aparición de 2 cráteres el 5 de enero del 2010. b Unión de los cráteres formando uno solo llamado Boquete 1-2010, el 8 de enero del 2010.

1-2010, por lo que aumentó su tamaño a $125 \mathrm{~m}$ de diámetro mayor y $45 \mathrm{~m}$ de diámetro menor. Posteriormente, solo en los meses de abril del 2010 y enero del 2011, hubo reportes de pequeñas cantidades de caida ceniza en los alrededores del volcán.

Mediciones de temperatura en el Boquete 1-2010 indicaron una disminución: en enero del 2010 fue de $560{ }^{\circ} \mathrm{C}$ y en julio del 2011, utilizando la cámara térmica Flir ${ }^{\circledR}$ P660 se midió $306{ }^{\circ} \mathrm{C}$ (Ramírez et al., 2011; Fig. 6a-b). Sin embargo, en ese mismo mes, apareció en el fondo del cráter Murciélago un lago frío y en sus alrededores una zona fumarólica con temperatura de $531^{\circ} \mathrm{C}$ (fig. 6c-d), que coincide con el alineamiento de la falla Ariete. En este campo fumarólico se observaba incandescencia y $\mathrm{SO}_{2}$ en estado de combustión; adicionalmente, se forman a partir de este mes dos plumas de gas muy vigorosas, con fuerte sonido, que salen del flanco E del cráter Murciélago. Se logró estimar con la cámara térmica Flir® P660, la velocidad de la pluma de gas que es aproximadamente $60 \mathrm{~m} / \mathrm{s}$, cuando la dirección y velocidad del aire es poco significativa y se observó el enfriamiento paulatino de la columna de gas al ascender a la atmósfera, la cual pasa de $\sim 600^{\circ} \mathrm{C}$ a $25^{\circ} \mathrm{C}$, en un tiempo promedio de $6 \mathrm{~s}$ (Ramírez et al., 2011; fig. 6e-f).

En diciembre del 2012, según comentó el administrador del Parque Nacional Volcán Turrialba (PNVT) Sergio Guillén, aparece azufre de color negro a naranja, en la fumarola Árbol Quemado. El día 10 de enero del 2012, se visitó el cráter del volcán Irazú y desde ahí se hicieron mediciones del volcán Turrialba, debido a la cercanía entre los volcanes ( $\sim 10 \mathrm{~km}$ de distancia) y buena visibilidad del día. Se observó por medio de la cámara térmica Flir ${ }^{\circledR}$ P660, anomalías de temperatura en el costado externo W del cráter Murciélago, por lo que, al día siguiente se visitó la cima del volcán Turrialba. El 11 de enero del 2012, al muestrear la fumarola Árbol Quemado, se observó un extraordinario flujo de azufre activo tipo pāhoehoe, con levèes y lóbulos (fig. 7a-b), una longitud de 175 $\mathrm{m}$, un ancho promedio de $10 \mathrm{~cm}$ y temperatura de $\sim 90{ }^{\circ} \mathrm{C}$. Este flujo se originó por un sobrecalentamiento en el sistema hidrotermal, donde puede acumularse el azufre y al fundirse, refleja que el sistema aumentó de temperatura.

El día 12 de enero del 2011, se visitó nuevamente el volcán Turrialba y se observaron al menos cuatro nuevos flujos de azufre entre el día 11 y 12 de enero. En el momento de las mediciones se escucharon retumbos, acompañados de caída de bloques debido a la pérdida del ángulo de reposo, ocasionado por la vibración de los sismos superficiales. En la tarde del 12 de enero, el volcán hizo una nueva erupción freática, en la pared externa E del cráter NW, cerca de la fumarola Árbol Quemado, formando otra boca que se le llama Boquete 1-2012, con un diámetro mayor de 15 $\mathrm{m}$ y $10 \mathrm{~m}$ de diámetro menor (fig. $6 \mathrm{~g}-\mathrm{h}$ ). La altura de la columna de ceniza era de $250 \mathrm{~m}$, acompañada de pequeñas explosiones con salida de lapilli y bloques, además de $\mathrm{SO}_{2}$ en combustión e incandescencia (fig. 6g-h). Una nueva erupción freática se dio el día 18 de ese mismo mes en el Boquete 

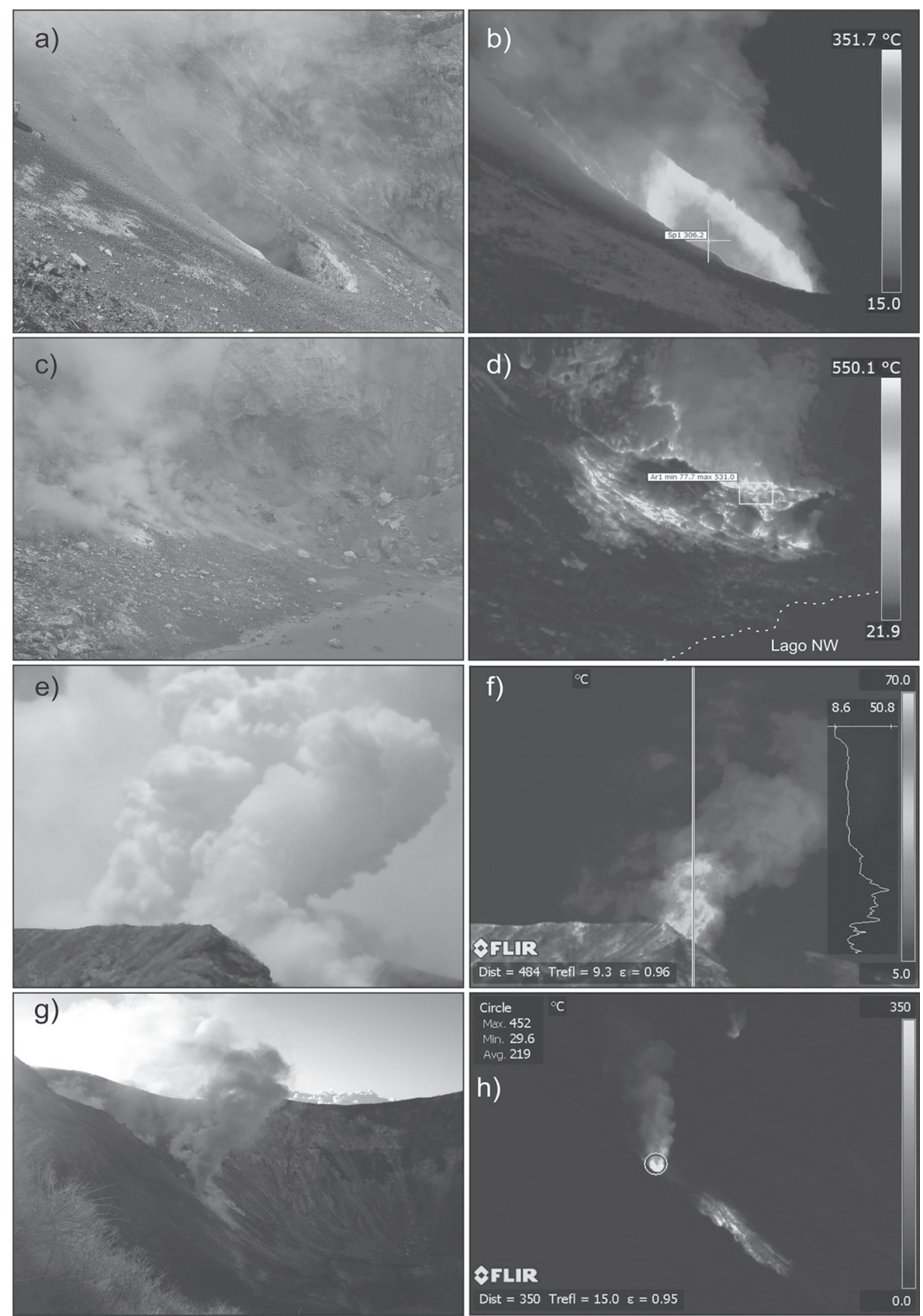

Fig. 6: Fotografías e imágenes térmicas respectivas de distintos puntos del volcán Turrialba, tomadas con la cámara térmica FLIR ${ }^{R}$ P660 y debidamente corregidas en el programa FLIR ${ }^{\circledR}$ Reporter. a Fotografía del Boquete 1-2010 en julio del 2011. b Imagen térmica del Boquete 1-2010 en julio del 2011. c Fotografía del fondo del cráter NW con su lago frío en julio del 2011. d Imagen térmica del fondo del cráter NW con su lago frío en julio del 2011. e Fotografía de la pluma de gas vista desde el mirador del volcán Turrialba en julio del 2011. f Imagen térmica de la pluma de gas vista desde el mirador del volcán Turrialba en julio del 2011. g Fotografía de la erupción freática del 12 de enero del 2012, en la cual se observa el Boquete 1-2012 y emisión de ceniza no juvenil a una altura de $250 \mathrm{~m}$. h Imagen térmica de la erupción freática del 12 de enero del 2012, se observa una zona de mayor calentamiento ubicada pendiente abajo al Boquete 1-2012 y el enfriamiento paulatino de los gases y la ceniza expulsada. 

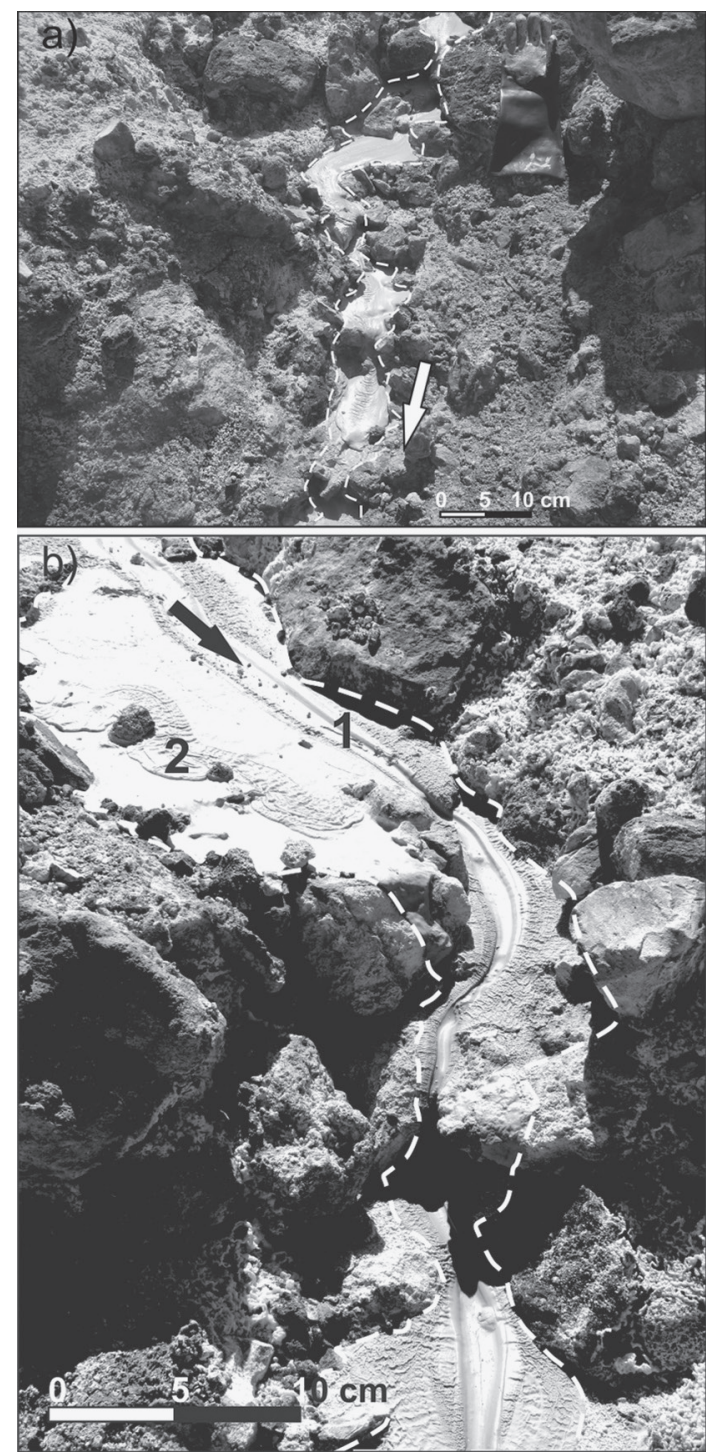

Fig. 7: Flujo de azufre activo del 11 de enero del 2012, tipo pāhoehoe, con una extensión de 175 metros de largo y ancho promedio de $10 \mathrm{~cm}$ y una temperatura de $\sim 90{ }^{\circ} \mathrm{C}$, con dirección de flujo hacia el E. a Cascadas y varios flujos de azufre, en donde se aprecia el flujo tipo pāhoehoe; flecha blanca: dirección hacia el E del flujo. b Características de este flujo: 1. levèes y 2 . lóbulos; la flecha en negro: dirección hacia el E del flujo.
1-2012, por lo que hubo un ensanchamiento de esta boca, aumentando a 25 metros de diámetro mayor y 15 metros de diámetro menor. La ceniza se pudo observar desde el volcán Irazú y el centro del cantón de Turrialba ( $\sim 15 \mathrm{~km}$ de distancia).

\section{DISCUSIÓN}

\section{Erupción 1864-1866}

Previo a la erupción magmática de 18641866, existe un registro de casi 20 años de descripciones, donde se reportaron retumbos, desgasificación, aparición de fumarolas, algunas hasta $>250{ }^{\circ} \mathrm{C}$, varias plumas de gas visibles a decenas de kilómetros de distancia del volcán Turrialba, gases azulados, incandescencia e inclusive erupciones freáticas (figura 3). Cuando inicia la erupción magmática, aumentó la lluvia ácida y una disminución de $\mathrm{pH}$ del río Toro Amarillo, además erupciones tipo estrombolianos a vulcanianos y que generó caída de ceniza hasta Puntarenas (fig. 4a). En términos de riesgo y vulnerabilidad, es importante conocer que sucedió en esta erupción, estimar los mayores peligros para la sociedad actual, ya que, para el siglo XIX la población y las tecnologías eran distintas a las actuales. Es fundamental estar preparados, si ocurriese un evento similar a la erupción de 1864-1866.

\section{Geoquímica de fluidos}

El $\mathrm{CO}_{2}, \mathrm{~S}_{\mathrm{t}}, \mathrm{H}_{2} \mathrm{O}, \mathrm{HCl}, \mathrm{HF}$ son gases determinantes para entender la evolución magmática (Delmelle \& Stix, 2000). En el caso del volcán Turrialba las proporciones entre las concentraciones de $\mathrm{SO}_{2}+\mathrm{H}_{2} \mathrm{~S} / \mathrm{CO}_{2}$ aumentaron y pasó de estar en una etapa hidrotermal magmática a dominancia magmática (Vaselli et al., 2010). Mediciones de la concentración de $\mathrm{SO}_{2}$ de la pluma de gas, 
utilizando el instrumento Mini-Doas, se reportan valores entre 700 a 2400 ton/día (Martini et al., 2010; Morales, 2011), estos valores son similares a otros volcanes del Arco Volcánico de Centro América (CAVA por sus siglas en inglés) como en el volcán Pacaya, Masaya y Santa Ana, los cuales son muy activos y con erupciones recientes (McGonigle et al., 2002; Rodríguez et al., 2004; Hernández et al., 2007). Además el aumento de este gas, provoca un incremento en la lluvia ácida, presente en los volcanes Masaya y Poás (Francis \& Oppenheimer 2004; Hansell et al., 2006; Mora et al., 2011b). En el caso del volcán Turrialba, los sectores más afectados por lluvia ácida son el SW, W y NW (Young, 2011; Soto, 2012). Los techos de las casas en La Picada, La Silvia y el Retiro (fig. 4b), presentan problemas de corrosión y por el aumento en la lluvia ácida y salida de gases, algunas personas han abandonado sus hogares e inclusive, la escuela de La Central fue cerrada en su momento por la falta de estudiantes. Además, la lluvia ácida ha producido clorosis, que ocasiona muerte de la vegetación (Young, 2011).

Baxter \& Kapila (1989) dividen en dos tipos los principales gases volcánicos de acuerdo con su reacción en los seres vivos: (1) irritantes $\left(\mathrm{SO}_{2}, \mathrm{HCl}, \mathrm{HF}, \mathrm{NO}_{\mathrm{x}}\right)$ y (2) asfixiantes $\left(\mathrm{CO}_{2}, \mathrm{CO}\right.$, $\mathrm{H}_{2} \mathrm{~S}$ ). Pobladores ubicados en los sectores $\mathrm{W}$ y SW del Turrialba reportan constante olor a azufre, que coincide con la dirección predominante de los vientos y por lo tanto hay una mayor concentración de $\mathrm{SO}_{2}$ en esta zona (Young, 2011). Otro factor importante es la densidad de los gases volcánicos con respecto al aire $\left(\mathrm{SO}_{2}, \mathrm{HCl}, \mathrm{NO}_{\mathrm{x}}\right.$ $\mathrm{CO}_{2}, \mathrm{y} \mathrm{H}_{2} \mathrm{~S}$ son más densos que el aire), estos tienden acumularse en depresiones, trincheras o valles con poca oxigenación (Hansell et al., 2006). Como muestra el mapa de lluvia ácida de Soto (2012), en sectores como la Esperanza y finca la Caridad ubicados a $\sim 7 \mathrm{~km}$ del volcán (SW del volcán) presentan valores de $\mathrm{pH}<4$, por estar ubicados en una depresión topográfica (Fig. 4b). Además la topografía en los alrededores del volcán presenta ondulaciones importantes, en las cuales se podría acumular estos gases tóxicos.

Los valores isotópicos de ${ }^{3} \mathrm{He} /{ }^{4} \mathrm{He}$ del volcán Turrialba, mostraron picos de 8,2 Ra (donde 1 $\mathrm{Ra}={ }^{3} \mathrm{He} /{ }^{4} \mathrm{He}$ del aire $=1,4 \times 10^{-6}$; Rouwet et al., 2010), este alto valor, sugiere una fuente magmática activa (Hilton et al., 2010; Martini et al., 2010; Vaselli et al., 2010) y es un poco más elevado a los medidos en otros volcanes del CAVA (Hilton et al., 2002; Rouwet et al., 2009).

\section{Ceniza}

Se analizó la ceniza de la erupción freática del 5 de enero del 2010, recolectada en el sector de La Central (fig. 4b). Esta presenta fuerte alteración hidrotermal: sus líticos eran de colores rojizos y cafés, con poca a nula vesicularidad. Se clasifica como ceniza no juvenil (es decir no hay presencia de magma fresco; Barberi et al., 1992). Reagan et al. (2011) explican que el $\sim 1 \%$ de esta ceniza presenta vidrios frescos, es decir juveniles, así como una inusual química, pero igualmente clasifican esta erupción como freática. Una erupción freática se refiere a la expulsión de material de la roca caja o líticos no juveniles por un calentamiento en el sistema hidrotermal (Cas \& Wright, 1987; Barberi et al., 1992; Schmincke, 2004). Asimismo, las erupciones del 12 y 18 de enero del 2012, se clasifican como freáticas. Utilizando difracción de energía de rayos $\mathrm{X}$ y difractometría de rayos X (fig. 8 y cuadro 3), se clasificó la ceniza del 5 de enero del 2010, en fase amorfa, compuesta por vidrio volcánico y fase cristalina ( $80 \%$ cristobalita y $20 \%$ de hematita). La cantidad de ceniza emitida ha sido pequeña, pero si llegan a ocurrir nuevas erupciones con un aporte importante de ceniza y una composición mineralógica similar, esta podría ocasionar problemas en la salud. La cristobalita es dañina cuando se inhala, es un 


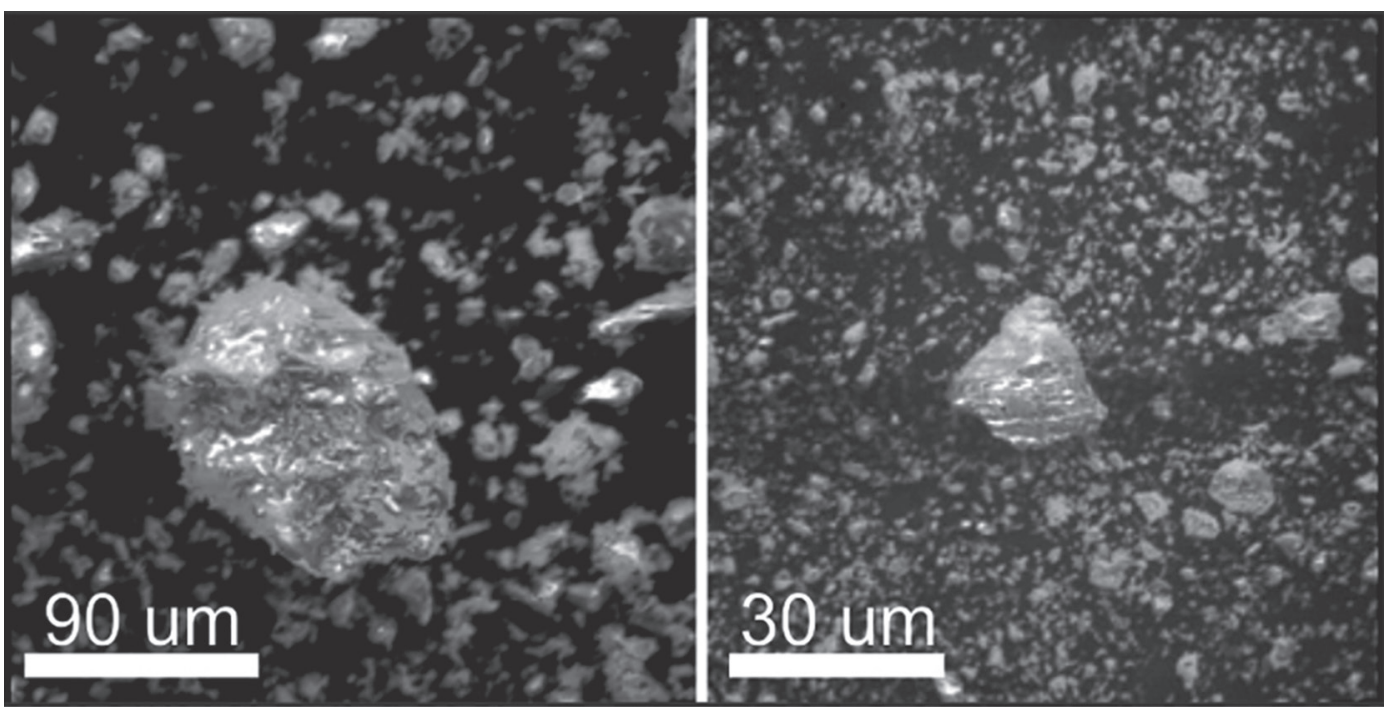

Fig. 8: Micrografía de la ceniza de enero del 2010 a distintas escalas; véase los tonos oscuros que corresponden con la fase amorfa compuesta por vidrio volcánico; los tonos claros corresponden con la fase cristalina compuesta por cristobalita ( $80 \%)$ y hematita (20\%).

carcinógeno y causa la enfermedad pulmonar llamada silicosis, que aumenta la posibilidad de contraer tuberculosis (Federal Coordinating Office, 1980; Hansell et al., 2006). Casos similares se presentaron en los volcanes Santa Helena en 1980 y Montserrat en 1995-1998 (Federal Coordinating Office, 1980; Baxter, 2000). El otro mineral es hematita que puede provocar problemas en pulmones y cáncer estomacal (Horwell \& Baxter, 2006).

Por su tamaño $(\leq 2 \mathrm{~mm})$, inhalar ceniza provoca irritación pulmonar y síntomas de asma, se han reportado en los volcanes Santa Elena en 1980, Pinatubo en 1991 y Montserrat en 1995, producto de las erupciones (Hansell et al., 2006).

En la sociedad actual y con el avance de las tecnologías, la ceniza de las erupciones volcánicas ocasiona daños en artefactos eléctricos, electrónicos, automóviles, aviación, etc (Gordon et al., 2005). Estudios detallados sobre el efecto de las cenizas en infraestructura, electricidad, maquinaria, abastecimiento de agua, población, vida silvestre, entre otros, fueron hechos durante la erupción del volcán Santa Elena en 1980 (Federal Coordinating Office, 1980). Es importante conocer la vulnerabilidad de los equipos a ser dañados, tomando en cuenta aspectos como la cantidad y composición de la ceniza. Cabe destacar, que las cenizas de la erupción de 1864-1866 y la erupción del 5 de enero del 2010, han llegado a San José y Cartago (fig. 4a-b), donde se centra más de la mitad de la población de Costa Rica.

\section{Vulnerabilidad}

Si asumimos que en los próximos años sucede una erupción similar a la ocurrida en 1864-1866, el área afectada sería aproximadamente $3400 \mathrm{~km}^{2}$ (figura 4a). El número de habitantes que serían afectados es de unos 2145 000. Además, la ceniza de la erupción de 1864-1866 cayó en las provincias de Cartago, San José, Heredia, Alajuela, Limón y Puntarenas, incluyendo unos 40 cantones. En infraestructura de primera respuesta, una erupción de este tipo, podría afectar 22 hospitales, 64 clínicas, 28 estaciones de bomberos y unos 1 370 centros educativos como posibles puntos de refugio. Estos datos se determinaron utilizando el SIG Arc GIS ${ }^{\circledR} 9.3$ y la base de datos del censo de Costa Rica del 2000.

Para la erupción freática del 5 de enero del 2010, se hizo un mapa de lluvia ácida y afectación por caída de ceniza, la cual cubrió un área de $500 \mathrm{~km}^{2}$ (Fig. 4a-b) y su espesor fue menor a 2 centímetros al SW y W del volcán. Al sobreponer el mapa de caída de ceniza de la erupción magmática de 1864-1866 y el de enero del 2010, 
Cuadro 3

Análisis químico por porcentaje de peso hecho en difractometría de rayos X para la ceniza del 5 de enero del 2010, tomada en La Central, al SW del volcán Turrialba (ver figura 4b)

\begin{tabular}{ccccccc}
\hline Spectrum & Oxígeno $\%$ & Sílice $\%$ & Hierro $\%$ & Calcio $\%$ & Potasio $\%$ & Zinc $\%$ \\
\hline 1 & 46 & 28 & 13 & 3 & 3 & n.d. \\
2 & 50 & 42 & 5 & 2 & 1 & n.d. \\
3 & 46 & 34 & 15 & 2 & 2 & 1 \\
\hline
\end{tabular}

las provincias que han sido afectadas por ambos eventos son San José y Cartago (fig. 4a-b).

Por el importante aumento en la actividad volcánica desde el 2005 y por el mal estado del camino hacia el volcán, se tomaron distintas medidas de seguridad, por ejemplo, en junio del 2009, se decidió por acuerdo entre la RSN y la CNE, prohibir la entrada de turistas al mirador del volcán. La RSN, creó un Semáforo Volcánico ubicando al Turrialba en 2a (cambios en el comportamiento de la actividad volcánica) y con la erupción del 2010, se elevó a color amarillo (erupción probable o cambios fuertes en la erupción en el término de días, semanas o pocos meses). Se evacuaron temporalmente a las personas que vivían en los alrededores del volcán, se generaron retenes para evitar la entrada de personas y vehículos a los lugares de mayor riesgo. La ceniza del 5 de enero del 2010, ocasionó la caída del fluido eléctrico en el poblado de La Central y alrededores, esto ocurre, debido a la obstrucción de la ceniza en los conductos eléctricos, hay un recalentamiento en el sistema y cae la electricidad (Federal Coordinating Office, 1980).

A pesar de que la actividad del volcán no disminuyó y el camino hacia la cima tenía pocas mejoras, en agosto del 2011, el PNVT se reabrió al público con algunas medidas de restricción para los visitantes.

Posteriormente, para la erupción de enero del 2012, el estado del volcán Turrialba se elevó a color amarillo, pero sin evacuar a la población. Se hicieron retenes, censo de población y animales que se encontraban en las zonas de mayor riesgo en ese momento, y se prohibió el acceso a la cima del volcán Turrialba indefinidamente por el Comité Asesor Técnico de Vulcanología, de la CNE.

\section{CONCLUSIONES}

El volcán Turrialba, se caracteriza por periodos largos de desgasificación y un aumento paulatino en su despertar. Según los registros de Diego de la Haya, antes de 1723, el volcán ya mostraba actividad de desgasificación, gases a altas temperaturas y posiblemente erupciones freáticas, pero se desconoce si tuvo alguna erupción magmática en aquella época. A su vez, la historia previa a la erupción magmática de 1864-1866, marca una evolución paulatina de al menos 20 años. El volcán fue cambiando, sus temperaturas aumentaron, incrementó la lluvia ácida, el escape de gases y erupciones freáticas. Se podría pensar, que el Turrialba es un volcán que presenta significativos cambios previos al hacer una erupción magmática y de ahí radica la importancia de tener el volcán bajo constante vigilancia.

Tras muchas décadas de no mostrar mayor atención, el volcán está cada vez más activo. A partir del 2005, el sistema se volvió más magmático, acompañado de cambios físicos y químicos, como el aumento de la temperatura en las fumarolas y dominancia de $\mathrm{SO}_{2}$, que es un gas de origen magmático. La actividad del volcán Turrialba, al mes de marzo del 2012, es desgasificación con dominancia magmática (Vaselli et al., 2010).

La ceniza expulsada el 5 de enero del 2010 , fue un volumen pequeño en comparación con la erupción de 1864-1866, pero cabe destacar que contiene minerales como cristobalita y hematita, perjudiciales para la salud. Si hay un aumento en la emisión de ceniza con similar composición química, se deben tomar medidas de mitigación contra posibles enfermedades pulmonares como la silicosis. 
A partir de la erupción freática del 5 de enero del 2010, el volcán Turrialba comenzó a liberar grandes cantidades de $\mathrm{SO}_{2}$, con una pluma de gas de color azul e incandescencia. Esta pluma ha llegado a observarse a $\sim 65 \mathrm{~km}$ distancia del volcán, que concuerda con el relato de von Frantzius (1861) explicando que, la pluma de gas en aquella época era visible desde esta distancia. Las fumarolas actuales son de alta temperatura e inclusive han aparecido zonas fumarólicas a más de $500{ }^{\circ} \mathrm{C}$, con fuerte sonido y $\mathrm{SO}_{2}$ en estado de combustión.

Con la erupción del 12 y 18 de enero del 2012, se mantuvo previa y durante el evento, una fuerte vigilancia del volcán, tal es así, que dos días antes de hacer erupción, se observaron cambios importantes en su actividad: aumento de la temperatura, aparición de nuevas fumarolas, azufre en estado de combustión en zonas donde antes no había, extraordinarios flujos de azufre y retumbos con caídas de bloques.

Los gases volcánicos (que se encuentran a altas temperatura e incandescentes) y la lluvia ácida, han sido hasta marzo del 2012, los principales problemas para los pobladores de los sectores S, SW y W del volcán. Algunos techos de las viviendas tienen corrosión, hay casas que han sido abandonadas e inclusive la escuela de $\mathrm{La}$ Central fue cerrada por la falta de estudiantes. Además, hay constante muerte de vegetación, esto es preocupante, ya que gran parte de la economía de la región es la producción lechera, ganadera y agrícola.

Basados en las experiencias históricas relatadas, la RSN realiza una constante vigilancia del volcán, principalmente en la parte geoquímica y sísmica. A la fecha, se ha comenzado a realizar mediciones de deformación volcánica, y se han intensificados las mediciones con sensores remotos, que según McNutt et al. (2000), estos parámetros son fundamentales para la vigilancia de un volcán activo. Como anota von Seebach (1865) y según los relatos antes descritos, el volcán Turrialba es uno de los principales focos eruptivos de América Central, por ende, debe estar en constante vigilancia y en caso de un cambio importante en su actividad, se debe informar a la CNE y población en general, para tomar las medidas correspondientes.

\section{AGRADECIMIENTOS}

A la Dra. Odalisca Breedy del Centro de Investigaciones en Estructuras Microscópicas (CIEMIC) de la UCR, por los análisis de difracción de energía de rayos $\mathrm{X}$ y al $\mathrm{M}$. Sc. Ricardo Montalbert de la Escuela de Química de la UCR, por los ensayos en difractometría de rayos $\mathrm{X}$ aplicados a la ceniza expulsada el 5 de enero del 2010. Agradecimiento especial a Gerardo J. Soto, Giovanni Peraldo y Mauricio Mora por los consejos, ideas, aclaración de dudas, discusión y revisión. Por su ayuda en el campo, información y amabilidad que siempre los caracteriza, se agradece a los compañeros guardaparques del PNVT. A las damas de la Biblioteca Nacional de Costa Rica, por la ayuda brindada con los textos históricos. Se agradece a las correcciones del texto a varios de nuestros amigos. Agradecemos a todas las personas que nos han acompañado en la gratificante labor de visitar el volcán Turrialba. Este trabajo se hizo bajo el proyecto de investigación de la Universidad de Costa Rica \#830A9-605 llamado "Vigilancia de los Volcanes Activos de Costa Rica".

\section{REFERENCIAS BIBLIOGRÁFICAS}

ALVARADO, G.E., 2009: Los volcanes de Costa Rica: Geología, historia, riqueza natural y su gente [3a edición].- 335 págs. Ed. UNED, San José.

BAXTER, P., 2000: Impacts of eruptions on human health.- En: SIRGURDSSON, H., HOUGHTON, B., MCNUTT, S., RYMER, H., STIX, J. (eds.): Encyclopedia of Volcanoes.- Academic Press, San Diego: 1035-1044.

BAXTER, P. \& KAPILLA, M., 1989: Acute health impact of gas release at Lake Nyos, Cameroon, 1986.- J. Volc. Geoth. Res. 39: 265-275.

BARBERI, F., BERTAGNINI, A., LANDI, P. \& PRINCIPE, C., 1992: A review on 
phreatic eruptions and their precursors.J. Volc. Geoth. Res. 52: 231-246.

BARQUERO, R. \& ROJAS, W., 2010: Resumen de la actividad sísmica y volcánica durante el año 2009.- 31 págs. RSN UCR-ICE [Informe interno].

CAS, R. A. F. \& WRIGHT, J. V., 1987: Volcanic Successions: Modern and Ancient.- 544 págs. Ed. Chapman and Hall, Londres.

DELMELLE, P. \& STIX, J., 2000: Volcanic Gases.En: SIRGURDSSON, H., HOUGHTON, B., MCNUTT, S., RYMER, H., STIX, J. (eds.): Encyclopedia of Volcanoes.Academic Press, San Diego: 803-816.

FEDERAL COORDINATING OFFICE, 1980: Mount St. Helens, Technical Information Network.- 130 págs. Federal Emergency Management Agency, E.E.U.U. [Informe interno].

FERNÁNDEZ, R., 1921: Un Volcán olvidado.Rev. Costa Rica, 4-5: 110-120.

FRANCIS, P. \& OPPENHEIMER, C., 2004: Volcanoes [2 ${ }^{\text {a }}$ edición].- 536 págs. Ed. Oxford University Press, Estados Unidos.

GONZÁLEZ, G., MORA, R. \& RAMÍREZ, C., 2010: Actividad Histórica del Volcán Turrialba (1846-2010), Costa Rica.La Antigua 2010, 10mo Congreso Centroamericano de Geología, Sacatepequez, Guatemala, 25.

GORDON, K. D., COLE, J.W., ROSENBERG, M. D. \& JOHNSTON, D. M., 2005: Effects of volcanic ash on computers and electronic equipment.- Natural Hazards, 34: 231-262.

GUILLÉN, D., (1988): Costa Rica: América Latina. Una historia breve.- 175 págs. Alianza Editorial Mexicana, México.
HANSELL, A. L., HORWELL, C. J. \& OPPENHEIMER, C., 2006: The health hazards of volcanoes and geothermal areas.Occup. Environ. Med. 63: 149-156.

HERNÁNDEZ, P. A., PÉREZ, N. M., VAREKAMP, J. C., HENRIQUEZ, B., HERNÁNDEZ, A., BARRANCOS, J., PADRÓN, E., CALVO, D. \& MELIÁN, G., 2007: Crater Lake temperature changes of the 2005 eruption of Santa Ana volcano, El Salvador, Central America.- Pure Appl. Geophys. 164: 2507-2522.

HILTON, D., RAMÍREZ, C., MORAAMADOR, R., FISHER, T., FÜRI, E., BARRY, P. \& SHAW, A., 2010: Monitoring of temporal and spatial variations in fumarole helium and carbon dioxide characteristics at Poás and Turrialba volcanoes, Costa Rica (20012009).- Geoch. J. 44: 431-440.

HILTON, D., FISCHER, T. \& MARTY, B., 2002: Noble gases and volatile recycling at subduction zones.- Rev. Mineral Geochem. 47:319-370.

HOFFMANN, C., 1856: Viajes por Costa Rica.En: Zeledón, E. (comp.) 1997: Viajes por la República de Costa Rica II.- Ed. Museo Nacional, San José: 163-207.

HORWELL, C. \& BAXTER, P., 2006: The respiratory health hazards of volcanic ash: a review for volcanic risk mitigation.- Bull. Volcanol. 69: 1-24.

MARR, W., 1853: Viaje a Centroamérica [Traducido por Reinhold, I.].- 472 págs. (2004).- Ed. UCR, San José.

MARTINI, F., TASSI, F., VASELLI, O., DEL POTRO, R., MARTINEZ, M., VAN DEL LAAT, R. \& FERNANDEZ, E., 2010: Geophysical, geochemical and geodetical signals of reawakening at Turrialba volcano (Costa Rica) after almost 150 years of quiescence.- J. Volc. Geoth. Res. 198: 416-432. 
McGONIGLE, A., OPPENHEIMER, C., GALLE, B., MATHER, T. \& PYLE, D., 2002: Walking traverse and scanning DOAS measurements of volcanic gas emission rates.- Geoph. Res. Let. DOI: 10.1029/2002GL015827.

MEAGHER, T., 1860: Holidays in Costa Rica, III.- En: VARGAS, J.C. (comp.) 2008: Tropical Travel: The representation of Central America in the 19th Century.- Ed. UCR, San José: 304-319.

MEYER, B., 1976: Elemental Sulfur.- Chemical Rev. 76: 367-388

MIYABUCHI, Y., SHIN-ICHIRO, I. \& KAZUNORI, W., 2008: Geological constraints on the 2003-2005 ash emissions from the Nakadake crater lake, Aso volcano, Japan.- J. Volc. Geoth. Res. 178: 169183.

MORA, M., ROJAS, W. \& LINKIMER, L. 2001: Resultados de una campaña sismológica realizada del 12 al 14 de marzo del 2001 en el volcán Turrialba, Costa Rica.- 13 págs + anexos. RSN UCR-ICE [Informe interno].

MORA, R., 2001: Informe Semestral de la actividad volcánica en la Cordillera Volcánica Central, Enero-Junio 2001.- 38 págs. RSN UCR-ICE [Informe interno].

MORA, R., 2003: Informe anual de la actividad de la Cordillera Volcánica Central, 2002, Costa Rica.- 50 págs. RSN UCR-ICE [Informe interno].

MORA, R., 2004: Informe de la actividad de la Cordillera Volcánica Central, Enero 2003 -Junio 2004.- 56 págs. RSN UCR-ICE [Informe interno].

MORA, R., RAMÍREZ, C. \& FERNÁNDEZ. M., 2004: La Actividad de los Volcanes de la
Cordillera Central, Costa Rica, Entre 19982002.- Rev. Geol. Amér. Central, 30: 189-197.

MORA, R. \& ROJAS, W., 2007: Reporte de actividad sísmica y volcánica del volcán Turrialba.- 8 págs. RSN UCR-ICE [Informe interno].

MORA, R., RAMÍREZ, C., GONZÁLEZ G., ROUWET, D. \& ROJAS, A., 2011a: Laguna Caliente, Poás Volcano, Costa Rica: The most active hyperacid crater lake of the world (2006-2011).- IAVCEI Commission on Chemistry of Volcanic Gases.- 11th Gas Workshop, Kamchatka, Rusia: 33.

MORA, R., RAMÍREZ, C. \& GONZÁLEZ G., 2011b: Informe de actividad de la Cordillera Volcánica Central (julio-octubre del 2011).- 15 págs. RSN UCR-ICE [Informe interno].

MORALES, A., 2011: Comparisons between $\mathrm{OMI} \mathrm{SO}_{2}$ data and ground-based SO2 measurements at Turrialba volcano.- 63 págs + apéndices. Michigan Technological University, E.E.U.U [Tesis M.Sc].

McNUTT, S., RYMER, H. \& STIX, J., 2000: Synthesis of Volcano Monitoring.- En: SIRGURDSSON, H., HOUGHTON, B., MCNUTT, S., RYMER, H. \& STIX, J. (eds.): Encyclopedia of Volcanoes.Academic Press, San Diego: 1165-1184.

NEWHALL, G. \& SELF, S., 1982: The volcanic explosivity index (VEI): An estimate of explosive magnitude for historical volcanism.- J. Geoph. Res. 87 (C2): 1231-1238.

OERSTED, A. S., 1863: L' Amerique Centrale: Recherches sur sa flore et sa Géographie Physique.- Imprenta Blanco Luna, Copenhague. 
PERALDO, G. \& MORA, M., 2008: Enseñanzas de la actividad histórica de los volcanes Irazú y Turrialba, Costa Rica, América Central.- En: GARCÍA, V., (coord.): Historia y desastres en América Latina III.Ed. RED, Panamá: 115-162.

PITTIER, H., 1888: Boletín Trimestral.- 62 págs. IGN [Inf. interno].

POLAKOWSKY, H., 1876: La República de Costa Rica.- En: Zeledón, E. (comp.) 1997: Viajes por la República de Costa Rica II.- Ed. Museo Nacional, San José: 207-313.

RAMÍREZ, C., MORA-AMADOR, R. \& GONZÁLEZ, G., 2010: Catalog of crater lakes from Costa Rica.- AGU Fall Metting, San Francisco, E.E.U.U., Abstracts \#V23A-2393.

RAMÍREZ, C., MORA, R. \& GONZÁLEZ G., 2011: Field thermal imaging monitoring of fumaroles, crater lakes and mud pools, at costa rican volcanoes.- 11th Gas Workshop, Kamchatka, Rusia: 40.

REAGAN, M., DUARTE, E., SOTO, G. \& FERNÁNDEZ, E., 2006: The eruptive history of Turrialba volcano, Costa Rica and potential hazard from future eruptions.- Geol. Soc. of Amer. S.P., 412: 235253.

REAGAN, M., ROWE, M., DUARTE, E. \& FERNÁNDEZ, E., 2011: Juvenile glass fragments in phreatic explosion debris from Turrialba volcano, Costa Rica.Goldschmidt conference, Praga, Rep. Checa: 1700.

RED SISMOLÓGICA NACIONAL, ICE-UCR 1991: Resumen de la actividad Sísmica y Volcánica de Costa Rica.- Rev. Geol. Amér. Central, 12: 103-108.
RED SISMOLÓGICA NACIONAL, ICE-UCR 1995: Resumen de la actividad Sísmica y Volcánica de Costa Rica.- Rev. Geol. Amér. Central, 18: 97-100.

RED SISMOLÓGICA NACIONAL, ICE-UCR 2001: Actividad Sísmica y Volcánica de América Central: Enero 1997-Diciembre 2000.- Rev. Geol. Amér. Central, 25: 107-113.

RODRIGUEZ, L. A., MATTHEW, I., ROSE, W., BRANAN, Y., BLUTH, G., CHIGNA, G., MATIAS, O., ESCOBAR, D., CARN, S. \& FISCHER, T., 2004: $\mathrm{SO} 2$ emissions to the atmosphere from active volcanoes in Guatemala and El Salvador, 1999-2002.- J. Volc. Geoth. Res. 138: 325-344.

ROJAS, W. \& PERALDO, G., 2009: Informe sobre visita al volcán Turrialba.- 6 págs. RSN UCR-ICE [Inf. interno].

ROUWET, D., INGUAGGIATO, S., TARAN, Y., VARLEY, N. \& SANTIAGO, J., 2009: Chemical and isotopic compositions of thermal springs, fumaroles and bubbling gases at Tacaná Volcano (México-Guatemala): implications for volcanic surveillance.- Bull. Volcanol. 71: 319-335.

ROUWET, D., MORA-AMADOR, R., RAMÍREZ, C. \& GONZÁLEZ, G., 2010: Hydrogeochemical model of the Irazú and Turrialba "twin volcanoes" (Costa Rica).- AGU Fall Metting, San Francisco, E.E.U.U., Abstracts \#V23A-2392.

ROUWET, D., MORA-AMADOR, R., RAMÍREZ, C. \& GONZÁLEZ, G., 2011: The dissapearance of Irazú cráter lake increased volcanic activity of neighboring Turrialba (Costa Rica)?.- 5th. Internacional Limnogeological Congress, Konstanz, Germany: 121-122. 
SAPPER, K., 1942: Viajes a varias partes de la República de Costa Rica (1899-1924).140 págs. Imprenta Universal, San José (Costa Rica).

SCHMINCKE, H. U., 2004: Volcanism.- 324 págs. Ed. Springer Verlag, Alemania.

SCOLAMACCHIA, T., PULLINGER, C., CABALLERO, L., MONTALVO, F., BERAMENDI, L. \& GONZÁLEZ, G., 2010: The 2005 eruption of Ilamatepec (Santa Ana) volcano, El Salvador.- J. Volc. Geoth. Res. 189: 291-318.

SOTO, G.J, 1986: Actividad histórica y predicción eruptiva del Volcán Turrialba.- $2^{\mathrm{a}}$ Jornada Geológica de Costa Rica, San José, Costa Rica: 6.

SOTO, G.J., MORA, R., MORA, M., BARQUERO, R., TAYLOR, W., VARGAS, A., ALVARADO, G.E., RAMÍREZ, C., GONZÁLEZ, G., MORA, R., PANIAGUA, C. \& FERNÁNDEZ, J.F., 2010: Turrialba volcano's threat to the cities of the Central Valley of Costa Rica.- 6th Cities on Volcanoes, Tenerife, España: 138.

SOTO, G.J., 2012: Mapa de acidez de lluvia alrededores del volcán Turrialba.- Escala 1:50 000, San José, RSN [Mapa inédito].

SPAMPINATO, L., SALERNO, G., MARTIN, R., SAWYER, G., OPPENHEIMER, C., ILYINSKAYA, E. \& RAMÍREZ, C., 2010: Thermal and Geochemical signature of Poás volcano, Costa Rica, (March 2009).- Rev. Geol. Amér. Central, 43: 171-190.
THEILIG, E., 1982: A primer on sulfur for the planetary geologist.- 34 págs. NASA 3594 [Informe Interno].

TRISTÁN, J.F., 1924: Dos documentos históricos.- 47 págs. Imprenta Lehmann, San José.

TROLLOPE, A., 1859: Las Indias Occidentales y el Continente Español.- En: FERNÁNDEZ, R. (comp.) 2002: Costa Rica en el Siglo XIX, Antología de Viajeros.- Ed. UNED, San José: 371-438.

VASELLI, O., TASSI, F., DUARTE, E., FERNÁNDEZ, E., POREDA, R. \& DELGADO, A., 2010: Evolution of fluid geochemistry at the Turrialba volcano (Costa Rica) from 1998 to 2008.- Bull. Volcanol. DOI: 10.1007/s00445-009-0332-4.

VON FRANTZIUS, A., 1861: Aporte al conocimiento de los Volcanes de Costa Rica.- En ZELEDÓN, E. (comp.) 1997: Viajes por la República de Costa Rica II.- Ed. Museo Nacional, San José: 19-162.

VON SEEBACH, K., 1865: Volcanes situados al Norte de las Tierras de Costa Rica. En: ZELEDÓN, E. (comp.) 1997: Viajes por la República de Costa Rica III.- Ed. Museo Nacional, San José: 17-31.

WAGNER, C. \& SCHERZER, S., 1856 [Traducido por Lines, J., 1944: La República de Costa Rica en Centro América.- 217 págs.].- Ed. MCJD, San José.

YOUNG, A., 2011: The Environmental Impacts of Volcán Turrialba's Plume, Costa Rica.- 77 págs. University of Cambridge, Inglaterra [Tesis M.Sc]. 
CITAS HEMEROGRÁFICAS

LA GACETA, 12 de marzo 1864, \#258: Ascensión al volcán Turrialba, en Costa Rica.

LA GACETA, 25 de setiembre 1864, \#285: Nota sobre la lluvia de ceniza
LA GACETA, 2 de octubre 1864, \#286: Nota sobre la lluvia de ceniza

LA GACETA, 9 de octubre 1864, \#287: El volcán de Turrialba y sus cenizas

LA GACETA, 4 de febrero 1865, \#303: Lluvia de ceniza. 